\title{
0 Vazio Estruturante da Mercadoria e do Pensamento em Marx e Hegel
}

\author{
Thiago Ferreira Lion ${ }^{1}$
}

Resumo: Este ensaio coloca em questão a solidez materialista da análise de Marx, não no sentido de que ela esteja incorreta, mas sim de que com sua análise da mercadoria o próprio núcleo do materialismo é revelado como algo "oco", como um vácuo que, no entanto, detém efetividade. É justamente este vazio estruturante da forma mercadoria que domina a matéria sem ter um único átomo em sua constituição - que é a condição de possibilidade de seu fetichismo. Essa concepção joga renovada luz sobre a relação de Marx com a teoria de Hegel e a estrutura conceitual da realidade ao mesmo tempo em que constitui uma crítica ao marxismo tradicional.

Palavras-chave: Hegel, Marx, Forma Mercadoria, Abstração Real, Espírito, Fetichismo.

Começo este curto escrito - no qual pretendo analisar um aspecto que julgo ser fundamental na obra dos grandes pensadores da dialética - com uma passagem na qual Marx, no prefácio da primeira edição de O Capital, acaba por dar uma dar uma prévia do que há de mais revelador em sua teoria:

\begin{abstract}
A forma do valor, cuja figura acabada é a forma do dinheiro, é muito simples e vazia de conteúdo. Mesmo assim, o espírito humano tem procurado fundamentála em vão há mais de 2000 anos, enquanto, por outro lado, teve êxito, ao menos aproximado, a análise de formas muito mais complicadas e replenas de conteúdo. Por quê? Porque o corpo desenvolvido é mais fácil de estudar do que a célula do corpo. Além disso, na análise das formas econômicas não podem servir nem o microscópio nem reagentes químicos. A faculdade de abstrair deve substituir ambos. ${ }^{2}$
\end{abstract}

O mais intrigante nesta passagem não é que Marx julga ter descoberto um segredo que perturba a humanidade há mais de dois mil anos, mas principalmente que a forma valor, da qual provém este segredo, é "muito simples e vazia de conteúdo". Como pode o núcleo do que se apresenta como segredo ser vazio de conteúdo? Esta inusitada

\footnotetext{
${ }^{1}$ Bacharel em Direito, Mestre em Direito Político Econômico e Doutorando em Filosofia. Editor da Revista Crítica do Direito e Especialista em Políticas Públicas do Estado de São Paulo. O presente artigo apresenta alguns pontos que o autor considera importantes, e que estão sendo desenvolvidos com mais detalhe em uma pesquisa mais ampla sobre a relação da análise da mercadoria com a dialética hegeliana.

${ }^{2}$ MARX, Karl. O capital. Livro I, Vol. I. São Paulo: Abril Cultural, 1983, p. 12.
} 
construção é retomada diversas vezes por Marx na mesma obra, como quando ele formula a seguinte pergunta na parte em que trata do "fetichismo da mercadoria": "De onde provém, então, o caráter enigmático do fruto do trabalho, tão logo ele assume a forma mercadoria?" ao que ele próprio responde de uma maneira completamente desconcertante: "Evidentemente, desta forma mesma"3.

O intrigante dessa resposta é que se espera a revelação do "algo que está por trás" da forma enigmática e, no entanto, o problema é justamente que não há nada por detrás. Como Marx faz questão de frisar, o segredo da mercadoria não está em alguma espécie de conteúdo que a forma valor esconda, mas na própria forma em que ela aparece. A aparência é desde já problemática, não precisando pressupor algo por detrás que "na realidade" seja diferente do que parece ser e assim constitua o problema. O problema é imediatamente visível. Basta lançar um olhar de espanto filosófico para se perceber que ocorre algo de muito estranho com o dinheiro, com esta forma abstrata e no entanto real que tudo pode comprar. Em nossos dias de intensa financeirização se torna patente que o dinheiro é muito mais que seu suporte físico, que a moeda ou o papel. O dinheiro é algo que inclusive pode prescindir de qualquer forma física, existindo como mero número na forma de crédito bancário, número mágico pelo qual acessamos praticamente todos os produtos de nossa sociedade.

Para progredirmos na compreensão desta forma, precisamos estabelecer alguns pontos talvez desconhecidos do leitor. Marx diferencia perfeitamente por um lado o conteúdo do valor, dada quantidade de trabalho e, por outro, sua forma, existente com base na estrutura da relação de troca. Muitas pessoas, entre elas inclusive muitas que se declaram marxistas, acreditam que a grande descoberta de Marx é que é o trabalho que produz valor, e que assim o que está "por detrás" da mercadoria é o roubo do valor do trabalho dos explorados pelos exploradores. O que tenho a dizer para estes é que subestimam Marx colocando num pedestal como seu grande mérito o que é acessível à compreensão sem grande esforço. O fato do trabalho gerar valor é conhecido nesta generalidade desde ao menos Adam Smith, e Marx foi muito além deste ponto. Se é para se chegar a este nível raso de conclusão realmente não há por que envolver Hegel e a dialética na análise.

Aqui iremos então deixar de lado esta questão do conteúdo do valor e nos focar no que Marx nos indica ser o mais enigmático e que constitui o núcleo de sua teoria

\footnotetext{
${ }^{3}$ Ibid., p. 71.
} 
madura: a análise da forma de mercadoria, a forma tomada em si mesma. Disse acima que ela está diretamente ligada à estrutura da troca, o que poderia gerar uma primeira objeção no sentido de afirmarem que minha posição é circulacionista, que abandono a questão da produção para me focar exclusivamente na relação de troca, mas lembro que evidentemente ao falar de troca falo de produção privada ${ }^{4}$.

Nos foquemos então no que interessa: a estrutura atemporal da troca de equivalentes. Duas pessoas se reúnem e igualam seus produtos, digamos trigo e leite, por meio de um ato de vontade, trocando sua titularidade. Se compararmos o trigo e o leite antes e depois da troca vemos que permanecem os mesmos. A troca não mudou diretamente nada na coisa em si, as propriedades físico-químicas continuam as mesmas, enquanto por outro lado o que ocorreu foi um evento carregado de significado em nossa ordem simbólica. A propriedade jurídica passou de uma pessoa para a outra de modo que cada um dos participantes tem em sua cabeça que a coisa que anteriormente era sua não é mais e que o que era do outro agora é seu. Um aperto de mão, uma assinatura ou a simples palavra dada selam a transferência da propriedade. Ela está dada antes mesmo da posse corpórea se efetivar e em tempos primitivos está sustentada sobre formas religiosas, de modo similar ao que hoje se sustenta sobre formas legais. Digo isso obviamente sem perder de vista a imensa diferença que há entre as complexas estruturas legais atuais e as formas rudimentares que vemos, por exemplo, na Grécia antiga. No que tem de mais geral, no entanto, ambas são a princípio coisas ideais no sentido de serem imateriais, só existindo por meio das ideias, ainda que estas sejam socialmente necessárias, isto é, que existam como objetividade na relação entre indivíduos. Ninguém consegue pegar fisicamente o direito e nem mesmo o Estado, sua essência é tão imaterial como qualquer outra coisa que se fundamente numa crença. Com a relação de troca nada muda diretamente na materialidade, a não ser por meio da mudança no pensamento dos participantes e daqueles que reconhecem a troca como válida conforme seus valores e crenças, sejam eles Zeus ou o Estado de Direito.

Daqui se vê porque a mercadoria é uma forma oca, sem conteúdo algum. Ela enquanto forma de valor tem uma carga puramente simbólica, que se dá diretamente apenas no pensamento dos agentes, um reino imaterial de pura abstração. É claro que de

\footnotetext{
${ }^{4}$ A relação de troca só pode existir com a produção privada, mas a produção privada como imaginamos também só pode existir com a troca no sentido em que se a produção é coletiva não há nada para ser trocado, pois tudo seria de todos. A relação de troca pressupõe a produção privada, da qual é parte necessária. Nos deteremos aqui na relação de troca, mas deve-se entender que ela sempre pressupõe uma forma de produção correspondente.
} 
maneira indireta vemos reflexo das trocas em toda a materialidade construída pelo humano e aqui precisamos fazer dois esclarecimentos. Este prédio em que estou foi construído por trabalhadores da construção civil, por pedreiros e aqui se vê diretamente uma transformação material. O que em primeiro lugar estou dizendo é que esta alteração material para ocorrer teve de ser mediada pelo pensamento que buscava, por sua vez, uma forma abstrata, ideal, que é o dinheiro. O dinheiro mesmo só pode existir se as pessoas nele acreditarem e isso nos leva ao segundo esclarecimento, que é o de que embora estes fenômenos como as leis e o dinheiro sejam ideais, envolvam uma espécie de objetividade efetiva. Estas formas tem estrutura de crença e não diretamente de algo material, mas ao mesmo tempo não são ideias subjetivas, mas ideias que compõe o próprio lastro de nossa experiência cotidiana de realidade.

Marx fala por diversas vezes dessa ausência de substância presente no valor, esta imaterialidade real que constitui sua forma, como quando diz que "em direta oposição à palpável e rude objetividade dos corpos das mercadorias, não se encerra nenhum átomo de matéria natural na objetividade de seu valor" ${ }^{\circ}$ e que nenhum físico com microscópio poderá encontrar o quanto vale determinado objeto. É uma relação oca, puramente formal, mas com imensos efeitos práticos do ponto de vista social. É uma espécie de princípio abstrato de organização da sociedade, mas que por ser objetivo e se comportar de maneira muito mais determinante que uma ideia comum é que é chamado hoje de Abstração Real, algo inimaginável para o pensamento formalista que entende o abstrato como meramente subjetivo e o real como mera objetividade exterior ao pensamento. Como disse Marx sobre as formas em $O$ Capital:

Tais formas constituem pois as categorias da economia burguesa. São formas de pensamento socialmente válidas e, portanto, objetivas para as condições de produção desse modo social de produção, historicamente determinado, a produção de mercadorias. Todo misticismo do mundo das mercadorias, toda a magia e fantasmagoria que enevoa os produtos do trabalho na base da produção de mercadorias, desaparece, por isso, imediatamente, tão logo nos refugiemos em outras formas de produção ${ }^{6}$

O que importa ficar claro aqui é que estas formas não são meramente reais no sentido serem materiais, sólidas, mas sim de serem abstrações objetivas. Como Marx diz, são "formas do pensamento socialmente válido" e, portanto, “objetivas para as condições (...) desse modo social de produção". Há no núcleo da mercadoria um vácuo, um fetichismo, uma crença, algo que mesmo não sendo material funciona, tem efetividade. Uma efetividade que é ideal, dependente de uma estrutura de pensamento.

\footnotetext{
${ }^{5}$ MARX, Karl. O capital. Op. Cit., p. 54.

${ }^{6}$ Ibid., p. 73
} 
A troca é uma abstração, abstração das qualidades dos produtos trocados, abstração das pessoas que trocam - tudo que conta é mais ou menos dinheiro, uma unidade matematicamente concebida. Esta abstração é, no entanto, não uma coisa meramente subjetiva, ao contrário, é o fundamento da própria objetividade social.

Em Hegel há uma estrutura simétrica a essa que vimos em Marx. Mas ao invés de partir da realidade externa e mostrar como ela é simbolicamente composta por uma abstração, por uma forma puramente imaterial, fazemos o caminho inverso. Partimos da mente e de seu caráter puramente abstrato para em seu desdobrar descobrirmos como é constituída a realidade externa. Chega-se à constatação de que é o próprio pensamento que designa a estrutura da realidade, que por sua vez é o limite do próprio pensamento. Esta afirmação, penso, deve ser suficiente para que os marxistas me excomunguem de seus círculos como mais um idealista. Lembro, no entanto, que falo aqui de ideias socialmente necessárias que constituem a estrutura basilar da sociedade, como o direito e o dinheiro e não de meros pensamentos individuais. Julgo que, ao menos em sua forma mais desenvolvida, esta afirmação corresponde ao pensamento de Marx, como aqui exponho em seus traços mais gerais.

Adentremos diretamente no assunto hegeliano por meio do exemplo. Eu penso em uma cadeira, em meu cérebro, sabe-se lá por quais pulsos elétricos e reações químicas forma-se a ideia de uma cadeira. Esta cadeira de facto se materializou em minha cabeça ou em algum lugar exterior? Pergunto no sentido de que as diferentes moléculas que formam a madeira, os metais dos pregos que unem as tábuas, a espuma do estofado e o tecido que o reveste realmente surgiram "do nada" a partir de meu pensar e amoldando-se fizeram brotar a cadeira? Óbvio que não, a cadeira é apenas uma ideia em minha cabeça, um "puro desvanecer" que no instante posterior já não é. O pensar, justamente por operar não com a matéria em si, mas com ideias, com universais, é assim necessariamente abstrato. Abstrai da materialidade e procura reconstituí-la internamente por meio de universais.

É por isso que o pensamento nunca alcança a coisa em si, como sempre postulou a filosofia moderna ainda que sem compreender com clareza o motivo. Sempre que a consciência julga tomar o objeto já não é ele, mas a si mesmo como pensamento que tem para si:

Essa maneira de ser do interior está imediatamente em consonância com [a opinião de] alguns, de que o interior incognoscível; só que o motivo disso deveria ser entendido diversamente. Sem dúvida, não pode haver nenhum 
conhecimento desse interior, tal como ele aqui é imediatamente; não porque a razão seja míope ou limitada, ou como queiram chama-la (...), mas pela simples natureza da Coisa mesmo: justamente porque no vazio nada se conhece; ou, expressando do outro lado, porque esse interior é determinado como o além da consciência. $^{7}$

Ser este espaço vazio, ávido por ser preenchido com objetos ideais, é que caracteriza o pensamento. As coisas que aparecem para ele são constituídas por ele mesmo, já que não é a cadeira em si que está na consciência, mas apenas sua representação, a pura forma do universal que se molda no vácuo do pensamento. No entanto, Hegel não é mais um idealista para o qual as coisas só existem perante a consciência. A questão para ele é colocada de maneira oposta: as coisas que podemos pensar e falar são as que nos aparecem no pensamento, é certo que haja um exterior, algo além destas coisas, mas este não é acessível justamente por ser definido como o que não está no pensamento. Não há, assim, interior algum a ser visto ${ }^{8}$. Por isso, como ele diz, trata-se de analisar justamente o que aparece, como diz Hegel:

A consciência distingue algo de si e ao mesmo tempo se relaciona com ele; ou, exprimindo de outro modo, ele é algo para a consciência. $\mathrm{O}$ aspecto determinado desse relacionar-se - ou do ser de algo para uma consciência - é o saber. Nós, porém, distinguimos desse ser para um outro o ser-em-si; o que é relacionado com o saber também se distingue dele e se põe como essente, mesmo fora dessa relação: o lado desse Em-si chama-se verdade. O que está propriamente nessas determinações não nos interessa [discutir] mais aqui; pois nosso objeto é o saber fenomenal, suas determinações são também tomadas como imediatamente se apresentam; e, sem dúvida, que se apresentam como foram apreendidas ${ }^{9}$

Aqui o paralelo com a análise da mercadoria de Marx começa a se revelar. Não é que devamos buscar a verdade para além desta forma que aparece, como se ela fosse uma mistificação que esconde a realidade por detrás. É nesta forma mesma de aparência que está a única realidade que nos é acessível pelo pensamento e que nos interessa compreender. No núcleo da relação mercadoria como no pensar existe um vácuo, um puro vazio que dá a forma, que estrutura a aparência ao seu redor. O problema não é descobrir o que é este vazio que está por detrás, pois ele é apenas isso, um puro vazio. O problema é descobrir porque justamente esse vazio aparece sob determinada forma. Aqui está a questão mais relevante sobre o Espírito hegeliano, aqui se debate a análise

\footnotetext{
${ }^{7}$ HEGEL, Georg Wilhelm Friedrich. A Fenomenologia do Espírito. Petrópolis, RJ: Vozes, $6^{\text {a }}$ ed., 2002. § 145.

8 “Levanta-se, pois, essa cortina sobre o interior e dá-se o olhar do interior para dentro do interior: o olhar do homônimo que a si mesmo se repele, e se põe como interior diferente; mas para o qual também se dá, imediatamente, a não diferenciação dos dois - a consciência-de-si. Fica patente que por trás da assim chamada cortina, que deve cobrir o interior, nada há para ver; a não ser que nós entremos lá dentro - tanto para ver como para que haja algo ali atrás que possa ser visto.” Ibid., §165.

${ }^{9}$ Ibid., § 82 .
} 
da mercadoria e, diga-se de passagem, aqui reside o problema psicanalítico do sujeito e seu desejo.

O antagonismo social capitalista é muito profundo e complexo e envolve em seu núcleo essencial o fetichismo da mercadoria, uma forma de não consciência social que estrutura a prática de todos os indivíduos e acaba por formar uma espécie de entidade metafísica universal que domina e produz os indivíduos singulares num sentido muito similar ao espírito hegeliano. Este ser supra-individual que em seu desdobrar produz os indivíduos é descrito por Hegel da seguinte maneira:

Segundo minha concepção - que só deve ser justificada pela apresentação do próprio sistema - tudo decorre de entender e exprimir o verdadeiro não como substância, mas também, como sujeito. Ao mesmo tempo, deve-se observar que a substancialidade inclui em si não só o universal ou a imediatez do saber mesmo, mas também aquela imediatez que é o ser, ou a imediatez para o saber ${ }^{10}$.

Uma totalidade na forma de sujeito-substância, algo que congrega a passividade objetiva com a atividade subjetiva e que ao se repor se automovimenta. Esta totalidade viva que é o todo, o universal, mas não em oposição ao singular. $\mathrm{O}$ universal que só é no singular e o singular que só o é como parte de um universal, como continua a explicar Hegel em sua concreta exposição especulativa:

A substância viva é o ser, que na verdade é o sujeito, ou - o que significa o mesmo - que é na verdade-efetivo, mas só na medida em que é movimento do pôr-se-a-si-mesmo, ou a mediação consigo mesmo do tornar-se outro. (...) Só essa igualdade reinstaurando-se, ou só a reflexão em si mesmo no seu ser-Outro, é que são o verdadeiro; e não uma unidade originária enquanto tal, ou uma unidade imediata enquanto tal. O verdadeiro é o vir-a-ser de si mesmo, o círculo que pressupõe seu fim como sua meta, que o tem como princípio, e que só é efetivo mediante sua atualização e seu fim ${ }^{11}$

Não é esta uma das mais adequadas exposições da lógica do Capital que faz o tempo histórico mover-se aceleradamente ao buscar sempre a si mesma na forma de dinheiro que procura mais dinheiro? É deste modo absolutamente similar que Marx ao partir da mercadoria demonstrará sua transformação em capital. O valor, antes mera mediação entre mercadorias, torna-se agora "valor em processo, dinheiro em processo e, como tal, capital", estabelecendo assim que a utilização do dinheiro para fazer mais dinheiro, D-M-D, “é a fórmula geral do capital”. Ao demonstrar o movimento a partir desta fórmula revela também que o capital é um sujeito automático que atende ao mesmo funcionamento do sujeito-substância hegeliano, um autômato unindo subjetividade viva e objetividade morta em seu automovimento:

\footnotetext{
${ }^{10}$ Ibid., $\$ 17$.

${ }^{11}$ Ibid., $\$ 18$.
} 
Na circulação D-M-D (...) mercadoria e dinheiro funcionam apenas como modos diversos de existência do próprio valor: o dinheiro como seu modo geral, a mercadoria o seu modo particular, por assim dizer apenas camuflado, de existência. Ele passa continuamente de uma forma para a outra, sem perder-se nesse movimento, e com isso, transforma-se num sujeito automático. Fixadas as formas particulares de aparição, que o valor que se valoriza assume alternadamente no ciclo de sua vida, então se obtém as explicações: capital é dinheiro, capital é mercadoria. De fato, porém, o valor se torna aqui o sujeito de um processo em que ele, por meio de uma mudança constante das formas de dinheiro e mercadoria, modifica sua própria grandeza, enquanto mais-valia se repele de si mesmo enquanto valor original, se autovaloriza. Pois o movimento, pelo qual ele adiciona mais-valia, é seu próprio movimento; sua valorização é, portanto, autovalorização. ${ }^{12}$ (grifo nosso)

Este imperativo de lucro, de autoexpansão do valor pelo valor que caracteriza o capital não é algo diretamente material. Antes é uma ideia, um imperativo abstrato que se perpetua por meio da coerção de nossas relações que as repõem como necessidade ao colonizar cada novo indivíduo nascido. Ao nascer não temos o capital como realidade e bebês se comovem com o dinheiro o mesmo tanto que com uma folha de papel - como também ocorre com os animais. Apenas nossa filiação posterior nesta ordem simbólica e que nos coloca a todos como indivíduos capitalistas, indivíduos profundamente marcados pela lógica do capital. Esta coisa ideal que é o valor se estabelece e se multiplica por meio de nossas relações, e com seu desdobrar ditando as necessidades e a atividade de bilhões de seres humanos o próprio mundo material é construído à sua semelhança. Florestas são destruídas e gigantescos edifícios brotam da necessidade instaurada por esta ideia que assim se materializa como realidade em todos os sentidos. Este é o auge das relações fetichistas que nos acompanham desde que o homem começa a desenvolver sua consciência e se separar da realidade.

O totemismo, as religiões e a mercadoria são exemplos de diferentes processos de fetichização de relações, mas que paradoxalmente se apresentam ao mesmo tempo como desfetichização. Estas relações ao se desenvolverem implicam maior conhecimento da realidade e assim da expansão, ao menos relativa, da capacidade de decidir, de se colocar como sujeito. Poderia se dizer que os modos de subjetivação se tornam mais plurais. A consciência nasce desde já alienada, mas esta forma mesmo é um processo de esclarecimento. O totem é uma relação fetichizada, mas não no sentido de ser meramente ilusão negativa, mas sim como forma necessária do desenvolvimento da consciência. Na religião monoteísta vemos, comparado com o totem, uma forma muito mais complexa de entendimento do mundo, ligada à forma infinitamente mais complexa de estrutura social. Na mercadoria este processo chega ao auge e o que era

\footnotetext{
${ }^{12}$ MARX, Karl. O capital. Op. Cit., p. 54.
} 
projetado no céu, agora se direciona para a terra. A estrutura metafísica agora não aparece mais em direta oposição ao mundo real, como existindo separado deste, mas antes "cola" nas próprias coisas, constituídas agora como sendo as próprias relações, como explica Marx em uma passagem dos Grundrisse:

Essas relações de dependência coisal, por oposição às de dependência pessoal (a relação de dependência coisal nada mais é do que as relações sociais autônomas contrapostas a indivíduos aparentemente independentes, i.e, suas relações de produção recíprocas deles próprios autonomizadas) aparecem de maneira tal que os indivíduos são agora dominados por abstrações, ao passo que antes dependiam um dos outros. A abstração ou ideia, no entanto, nada mais é do que a expressão téorica dessas relações materiais que os dominam. As relações só podem naturalmente ser expressas em ideias, e é por isso que os filósofos conceberam como o peculiar da era moderna o fato de ser dominada pelas ideias"13

As relações sociais, algo imaterial, agora se dão largamente por meio de uma forma material, o corpo sólido da mercadoria, e isso gera a disjunção valor/valor de uso, o metafísico do valor que acompanha diretamente a materialidade do corpo da mercadoria. É só pela remodelagem deste suprassensível "espiritual" nas coisas materiais que o capitalismo funciona.

Aqui está a dificuldade da análise da mercadoria, que funciona como uma síntese do que acontece na superfície da realidade e que acaba assim por recolocar a análise hegeliana em um nível mais adequado para compreendermos os processos que averiguamos na superfície da realidade. Acessamos diretamente apenas os fenômenos, então esse "real" que a análise apresenta não é algo que esteja "por detrás", mas sim o próprio fenômeno em si, do qual sua forma simples de apreensão é o nexo sintetizador, o "destilado" pelo qual o entendimento pode capturar a complexidade do mundo. Nisso, se retiramos a estrutura de crença em torno de figuras como totem, dinheiro, estado, já não resta como explicar nada, aparecem como coisas em si e para si e portanto sem explicação como um religioso encara Deus. É só percebendo sua vacuidade carente de sentido que podemos criticamente abordá-las e assim lhes dar, ainda que pela negativa, sentido. Daí que se depreende que sentido é algo humano, uma criação ainda inacabada e que, a realidade só terá sentido quando o sentido se tornar realidade.

No mundo humano as práticas se mantém a partir de um determinado modo de pensar que aprendemos e reproduzimos junto com elas mesmas. Se todos acordássemos com mentalidade feudal amanhã, desconsiderando o dinheiro e louvando a Deus nas formas antigas, não haveria modo do capitalismo continuar. A prática determina o

\footnotetext{
${ }^{13}$ MARX, Karl. Grundrisse: Esboço da crítica da economia política. São Paulo: Boitempo Editorial,
} 2011, p. 112. 
pensamento e o pensamento determina a prática, mas não individualmente e sim como uma necessidade. Esta não é nem puramente natural e nem puramente social, mas ambas as coisas ao mesmo tempo e uma só enquanto a outra também é. Tentar separar a prática do pensamento é como tentar separar a vida humana do fato de o humano pensar, como se o pensamento pudesse existir sem vida e como se uma vida que se caracteriza como humana pudesse se realizar sem o pensamento. $\mathrm{O}$ homem é um animal social apenas sendo um animal teórico, isto é, que de algum modo, coerente ou não, teoriza sua vida a partir do que apreendeu. A estrutura simbólica pressupõe algum nível, ainda que muito primitivo ou infantil, de significação e esta é parte constituinte direta de sua prática. É aqui que a religião e que a ciência se desdobram, dando sentido para aquilo que é um vazio, simbolizando e assim trazendo para o entendimento, para o nível da linguagem aquilo que antes era puramente em si. Esse trazer para si é, ao mesmo tempo um projetar-se nas coisas, pois só se percebe aquilo com o que se relaciona e assim se identifica. Esta relação entre o mundo material da vida e o mundo etéreo do pensar só pode existir separada no próprio pensamento que apenas imagina e que não sabe que em sua constituição ele mesmo não é algo separado, ou seja, que sua própria imaginação está condicionada por sua prática.

O pensamento é um desvanecer, uma abstração que em si não forma o material. Nesta ligação entre pensamento e prática que estrutura o mundo humano, vemos que o vazio do pensamento penetra justamente como um componente estruturante, como se algo sólido fosse, pois para se poder estruturar é necessário que seja assim tomado. Se em massa identificarmos judeus como responsáveis pela decadência social, podemos matar milhões deles em câmaras de gás. Não há nada de sólido ou diretamente material na base desse acontecimento brutalmente real - como em geral não há mesmo nas crises na qual a carência de alimentos depende da mediação ideológica da falta de perspectiva de lucro - mas apenas o vazio do pensamento recolocado como estruturante do mundo prático humano. Os humores do mercado são tão materiais como a vontade do Deus de Abraão, ainda que ambos operem de maneira diferente. A maleabilidade do pensamento por ser vazio determinante é a base das desgraças e ao mesmo tempo, da possibilidade de emancipação, do "ponto mágico" em que tudo se transforma, o que seria impossível se a âncora da realidade fosse plenamente sólida. É claro que o fato de não haver solidez material que a sustente não torna esta realidade menos dura, já que o simbólico tem como seu subordinado a efetividade da fome e de um sistema prisional ou toda a materialidade destrutiva de uma bala de fuzil. 
Sem se compreender que esta forma é oca e que seu segredo não está no vazio, mas em sua própria estrutura enquanto forma, o pensamento e a prática se tornam reféns destas abstrações. Tendem a projetar algo neste espaço como se assim pudesse capturar o que lhe é essencial ao confundir o vácuo com o objeto que nele aparece. No vazio se insinua o sagrado, o fetiche que justamente tenta apreender e dar sentido à esta falta constitutiva, a este vácuo primordial. Os rituais para a divindade, os rituais de cumprimento de uma legalidade estrita por muitas vezes absolutamente injusta, o supremo ritual do trabalho por 44 horas semanais necessário para aumentar a riqueza abstrata armazenada numericamente em computadores.

É justamente pela consciência social tomar como sólidas dadas formas de pensamento é que estas formas de pensamento adquirem realidade externa. A ideologia aqui deve ser compreendida de maneira muito diversa do que faz o marxismo tradicional com sua tradicional divisão entre base e superestrutura. Não é que exista uma realidade econômica "material em sentido estrito" e formas de pensamento superestruturais que a impedem de ser percebidas. Não é que a religião ou a igualdade formal jurídica sejam meras formas de esconder a exploração que existe de "fato" e que estariam sendo escondidas pelas formas superestruturais, mas são estas formas mesmas de consciência que possibilitam a exploração existir. A ideologia não é mera mistificação da "realidade material" que está "por detrás", antes é ela mesma a estruturadora desta realidade na forma em que esta aparece.

É também neste sentido de formar uma realidade exterior por meio do pensamento socialmente necessário que devem ser tomados os dizeres de Hegel de que “O entendimento percebente não chega à consciência de que tais essencialidades simples são as que nele dominam; mas acredita estar lidando sempre com matérias e conteúdos perfeitamente sólidos" ${ }^{14}$. A fixação do pensamento em determinações abstratas que julga ser o real objetivo, como o valor e em menor intensidade a lei, faz justamente com que essas abstrações se tornem realidade. De fato, se ninguém levar em consideração a lei, ela não existirá, do mesmo jeito que se ninguém acreditasse no dinheiro, ele automaticamente desapareceria. A realidade social aparece assim como imanente ao pensamento justamente no ponto em que este pensamento é unidade com uma prática social, ambos percebidos não só como o real, mas também e principalmente como um real necessário. Aqui cabe perfeitamente a famosa fórmula de Marx para a

\footnotetext{
${ }^{14}$ HEGEL, Georg Wilhelm Friedrich. A Fenomenologia do Espírito. Op. Cit., $\$ 131$.
} 
ideologia e o fetichismo em O Capital "Não o sabem, mas fazem" ${ }^{15}$ : há uma espécie de inconsciente que estrutura a prática, o que, desde o princípio, pressupõe uma mediação da prática pelo pensamento.

E como se livrar desta imanência no pensamento, como superar o fetichismo em nossas relações? Talvez a resposta de Hegel para a pergunta sobre a diferença da filosofia em oposição ao senso comum que "acredita estar lidando sempre com matérias e conteúdos perfeitamente sólidos" forneça uma pista:

Sem dúvida, a filosofia lida também com isso, e reconhece os entes de razão como puras essências, como absolutos elementos e potências. Mas, sendo assim, reconhece-os, ao mesmo tempo, na sua determinidade e deles se assenhora; enquanto aquele entendimento percebente os toma pelo verdadeiro, e por eles é jogado de erro em erro ${ }^{16}$.

A consciência trabalha apenas com as abstrações, ainda que julgue estar tratando de algo evidente, material, real. Isto deve ser radicalmente aceito, pois é apenas por meio desta aceitação que podemos nos desvincular de tomar estas abstrações como verdades em si e para si, podendo então reconhece-las como produto nosso e assim dominá-las para as utilizar corretamente. Isto que se passa com a linguagem, que deve ser mobilizada em sua estrutura abstrata contra seu próprio caráter fetichizante fornece um modelo que devemos utilizar contra a reificação das próprias instituições de nossa sociedade. $\mathrm{O}$ fato da realidade humana ser constituída de maneira simbólica deve ser radicalmente aceito, nos afastando da ideologia de um retorno a um pseudosubstancialismo, existente hoje em matizes tão variadas. Só quando esta realidade abstrata exterior for entendida como abstração gerada por nós mesmos é que as figuras fetichizantes como o valor e a lei poderão sair de cena, e aí, como diz Hegel no fim da sua introdução à Fenomenologia:

"A consciência, ao abrir caminho rumo à verdadeira existência, vai atingir um ponto onde se despojará de sua aparência: a de estar presa a algo de estranho, que é só para ela, e que é como um outro. Aqui a aparência se torna igual à essência, de modo que sua exposição coincide exatamente com esse ponto da ciência autêntica do espírito. E, finalmente, ao apreender sua verdadeira essência, a consciência mesma designará a natureza do próprio saber absoluto" 17

Os indivíduos estarão então emancipados do aprisionamento categorial, deixado para trás com a pré-história da humanidade, e finalmente se inscreverá na própria realidade de suas relações o princípio "de cada um conforme sua capacidade, à cada um conforme suas necessidades".

\footnotetext{
${ }^{15}$ MARX, Karl. $O$ capital. Op. Cit., p. 72.

${ }^{16}$ HEGEL, Georg Wilhelm Friedrich. A Fenomenologia do Espírito. Op. Cit.\$131.

${ }^{17}$ Ibid., § 89 .
} 